\title{
Enacting the utopia of eradicating homelessness: Toward a new generation of activity- theoretical studies of learning
}

\author{
Annalisa Sannino, Tampere University \\ Annalisa.Sannino@tuni.fi
}

\begin{abstract}
Eradicating homelessness is one of the most pressing challenges for efforts aimed at equity and social justice in the world. Many people who experience homelessness have histories of violence, growing up in child protection institutions, involvement in criminal activities, and mental and health problems connected with substance abuse. Homelessness is therefore a phenomenon which requires coherent and consistent cross-sectoral service integration and interorganizational service production. The way this challenge has been addressed so far in Finland may be interpreted as enacting a utopia when compared with other realities and the predominant views of impossibility to eradicate homelessness which stem from them. The article drafts an agenda aimed at disclosing how the utopia of eradicating homelessness is being enacted, what learning this involves, and how research on work and learning can concretely mediate and support the enactment processes.
\end{abstract}

\section{Keywords}

Enacted utopias, homelessness, Finnish Housing First, Change Laboratory, expansive learning, transformative agency, fourth generation activity theory

\section{Introduction}

Finland is a country which has set for itself the goal of eradicating homelessness by 2027. The Programme of Prime Minister Sanna Marin's Government published on December 10 2019 spells out that this goal will be pursued by continuing to operate according to the Housing First principle. This is the first time a Finnish government programme mentions Housing First, despite the fact that with this principle the country has distinguished itself as the only European nation that has been able to significantly reduce homelessness for a decade since 2008 (Abbé Pierre Foundation \& FEANTSA, 2018).

The Finnish Housing First (FHF) is an approach which started by the initiative of four activists and led to three interconnected national programs (Pleace et al, 2016). It consists in supplying affordable housing and tailored services to clients with complex problems and high need of social and health care (Y-Foundation, 2017). The Housing First principle states that living in one's own apartment is a precondition for a person to be able to overcome such complex problems. Only when a person has his or her own home, one realistically expect that targeted work on addictions, debts, mental health and crimes can be successfully undertaken. When looking at the transformative efforts taking place in this country since the first national programme, one gets a strong sense that what might appear as an impossibility can actually 
be realistically achievable. This orientation is what I call here the enactment of the utopia of eradicating homelessness.

There are numerous examples of research on work and learning engaged in locally-initiated transformative efforts for social justice. The field, however, still lacks coherent and robust frameworks to understand the dynamics of learning and agency involved in these efforts and how continuing educational approaches can concretely support them. Building on the concepts of expansive learning (Engeström, 1987/2015; Engeström \& Sannino, 2010; LotzSisitka, 2017) and transformative agency (Sannino, 2015ab; Kerosuo, 2017), this paper presents a draft of an unconventional research agenda and an example of a first implementation of it. Previous research on both expansive learning and transformative agency has so far focused on relatively circumscribed organizational contexts (e.g., Engeström, 2018; Sannino, 2015a) and boundary crossing settings (e.g., Kerosuo, 2006; Kerosuo \& Toiviainen, 2011). The agenda proposed here applies these theoretical resources to the context of the heterogeneous and nationwide distributed FHF.

The central questions motivating this agenda are the following: How do different sectors and organizations learn to enact utopias for equity and social justice? And, how can educational research concretely contribute to this learning? The article, in particular, uses as an example a first implementation of a research toolkit known as the Change Laboratory (CL, Virkkunen \& Newnham, 2013) on homelessness with the involvement of numerous sectors, organizations and different hierarchical levels. Three interconnected CLs were initiated to support the enactment of the utopia of eradicating homelessness in a phase of great uncertainty in Finland, when the third national programme was coming to an end in 2019.

The agenda presented here is a step forward in discussions within and across consolidated disciplinary traditions on utopias. It provides a novel multidisciplinary perspective which goes beyond prominent sociological and philosophical conceptualizations (Habermas, 2010; Levitas, 2000, 2003; Wright, 2010, 2016). Common to most of these foundational discussions is a focus on the feasibility of the envisioned outcomes. The present agenda, instead, focuses on uncovering the learning and agency processes by which a utopia for a more equitable world is being pursued.

The approach proposed here furthermore differs from the perspective of Levitas $(2001 ; 2003)$ which leads to a distinction between utopia as Popperian "blueprints" and utopia as a method (e.g. Eskelinen et al. 2017; Lakkala \& Pyykkönen, 2018). The example of the way in which the Change Laboratory toolkit was used to serve a critical transition phase toward a new programme helps exploring how utopia can be actually fostered in practice. This contribution is very timely, as the research literature on utopia is moving precisely to the direction of adopting utopias as critical means in learning to imagine and act beyond the prevailing system (e.g., Barkin, 2020; Bina et al, 2020). However, very little research is so far available on practices that might sustain this kind of capability to imagine and enable acting on utopias.

The agenda presented here also contributes to the ongoing educational and interdisciplinary discussions on participatory governance and co-creation (e.g., Brandsen et al., 2018). In response to the recent critical literature on the actual effects of current participatory practices (Steen et al. 2018), the learning for enacted utopias agenda represents a significant new development toward more detailed and nuanced understanding of these practices. Finally, differently from the dominant and widely available literature on individual learning and on the sense of agency (e.g., Schunk \& DiBenedetto, 2016), the agenda allows tracing the 
concrete collective processes of emergence and development of learning and agency, while at the same time practically supporting these processes.

\section{Enacting the utopia of eradicating homelessness with a research-mediated renewal of the Finnish Housing First principle}

The FHF strategy has ensured systematic nationwide development of expansive competences and knowhow, which have proven to be effective in responding to homelessness.

Professionals who have been retrained over these years have developed strong commitment to the cause of eradicating homelessness, and have been able to scale up changes at the local level towards a large, societal transformation. This is an internationally exceptional achievement (Henley, 2019), when in other countries the implementation of Housing First has primarily been carried out through isolated projects (Pleace et al, 2016). As such, the Finnish case stands out as a globally relevant instance of learning for the enactment of a utopia.

Despite its success, at the moment the strategy is particularly vulnerable. On the one hand, a generation change among administrators and practitioners makes the future of the FHF strategy uncertain. On the other hand, it has been found that the strategy is not sufficiently equipped to provide solutions specifically targeted at a radically increased diversity of clients (ARA, 2018) who also need services from multiple sectors. Furthermore, in recent years a particularly demanding group of clients has emerged which requires the heaviest and most diverse services and whose housing solutions have repeatedly failed. These clients require ways of working that go beyond what is already in place. It therefore appears that a significant cycle of learning has been accomplished since 2008 and a new cycle must start to push forward the enactment of the utopia.

A particular concern is currently with youth homelessness. The statistics show that in 2017, 1585 people under the age of 25 were homeless. In one year, youth homelessness increased by 186 people (Helskyaho, Ohisalo \& Turunen, 2018). Also, the Youth Housing Association (NAL) has estimated that in reality the number of homeless youth is much greater than these statistics show. This has led officials and actors involved in the Finnish homelessness strategy to consider youth homelessness as one of the most pressing issues to address (Karppinen, 2018).

Many of the young people who experience homelessness have histories of violence, growing up in institutions, involvement in criminal activities, and mental and health problems connected with substance abuse. There is an acute need to expansively transform youth homelessness services toward tailored and integrated solutions. More versatile solutions must be found with a stronger direct involvement of the key sectors of services related to substance abuse, mental health, debts and crime at the levels of frontline practices, the municipalities and the pertinent ministries. The implementation of the research agenda presented here seeks to help the forming of a new cross-sectoral alliance among key actors at the ground level and at the municipal level, which will have persuasive impact in interactions with state level actors.

Besides conceptualizing learning for the enactment of utopia, the theoretical tools at the core of the research agenda presented here also aim at supporting actual learning and agency 
formation processes, especially in phases of great uncertainty. For this, the agenda includes a set of interconnected spaces for collaborative analyses, design and discussions with frontline practitioners and city and state administrators. These spaces can be established by means of CL (Virkkunen \& Newnham, 2013).

Each step in an expansive learning cycle requires collective expertise. Although these steps can and are often accomplished by practitioners on their own, they can also be facilitated by formative interventions such as CL. Each CL consists of sessions in which the research team and the participants jointly analyze factors that hamper successful outcomes and co-design novel solutions. All sessions are video-recorded. Data across the levels are used as stimuli for joint analyses and design during the intervention sessions. The videotaped data stemming from the sessions are transcribed and analyzed using discourse analysis methods, specifically devised for conversations taking place in longitudinal CL interventions (Sannino, 2008; Engeström \& Sannino, 2011; Engeström, Rantavuori \& Kerosuo, 2013).

In these interventions expansive learning is triggered by opening up collective reflection on conflicting motives, for instance the motive of remaining within the frame of one's own sector and the motive to open up toward the unknown by experimenting novel solutions with other sectors. In the CL the conflicting motives are brought into the open by presenting to the participants evidence and examples of problems and disturbances within and across their work activities. These examples serve as first stimuli, often conveyed in the form of videotaped critical accounts, situations and encounters.

The participatory analyses and design in the CLs are carried out with the help of tools stemming from activity theory, such as the triangular model of the activity system, the cycle of expansive learning and the four-field depicting the collective zone of proximal development (Engeström, 1987/2015). These tools serve the identification of the systemic factors that led to the problem situations and the conflict of motives, to visualize evolving learning processes and a direction for the future.

\section{Fourth generation of activity theory as conceptual framework}

The conceptual framework of the agenda I am drafting here is situated within the perspective of the emerging fourth generation of activity theory. Research on learning in activity theory has evolved through a succession of three generations of theorizing focused on specific units of analysis. The first generation started with Vygotsky (1981) and used culturally mediated action as prime unit of analysis. In line with this unit of analysis learning is a process in which mediation by artefacts is essential. The second generation initiated by Leont'ev (1978; 1981) focused on activity as the unit of analysis. With this unit of analysis learning is seen as transformation of an activity, that is, a relatively durable collective system in which individual goal-oriented actions are distributed and combined to serve a shared motive (also called "object of activity") with the help of tools and rules. This unit of analysis has been modelled into a system in which the components defining an activity are represented as systemically interacting with one another (Engeström, 1987/2015). Studies in which the unit of analysis comprises multiple interconnected activities with partially shared objects represent a third generation of activity theory, in which learning is seen as involving interactions and negotiations between activities. 
Time is now mature for the development of a fourth generation activity theory. This should offer a unit of analysis able to grasp a qualitatively new type of activity formations and concerted efforts that can realistically meet the challenge of cross-sectoral service integration and interorganizational service production. As for the example presented in this article, this kind of service integration and service production are essential for eradicating homelessness.

Such a new step entails the involvement of a wide variety of actors at multiple levels - local, regional, national and possibly global. But, how might the unit of analysis of fourth generation activity theory look? The unit of analysis of the fourth generation looks like a web of coalescing heterogeneous work activities. Such heterogeneous activities, linked with urgent societal and humanitarian crises, represent crucial sites of inquiry for conceiving a fourth generation unit of analysis.

These activities are heterogeneous because they represent qualitatively different types of work and because they operate at different hierarchical levels in the society. These activities require one another to enact the shared utopia and their actors must learn to operate on the basis of concerted initiatives rather than only within their individual sectors and organizations and by top-down orientations. A fourth generation activity theory focuses on the study of the multiple learning cycles involved in and across these activities, their relative independent dynamics and their interdependency (Figure 1).

\section{INSERT FIGURE 1 ABOUT HERE}

Figure 1. A fourth generation activity theory unit of analysis for studying how learning for enacted utopias takes place and can be fostered

Over the past decade, the FHF strategy has developed through multiple interacting and overlapping learning cycles, which situate at multiple hierarchical levels and are both relatively independent and interdependent. They require one another to emerge and sustain themselves. They are meant also to operate across sectors of social services (housing, substance abuse, mental health, debts, and crime) represented by the different shades of colours in the cycles in Figure 1. The central learning cycle in Figure 1 is the one taking place among residents and frontline workers in supported housing units. These are usually recently built or newly renovated buildings with small apartments offered to homeless in great need of support. The residents have long-term or permanent rental agreements to live in these apartments. Practical nurses, social workers and registered nurses in the units have the task to help the residents realize jointly prepared rehabilitation or other life plans. The ethos of FHF is that everyone, no matter how complex his or her starting point might be when arriving in a supported housing unit, can learn to pay the rent, to clean the apartment and to make steps toward independent living.

The learning cycles of the housing units are directed and supported by the work of the NGOs responsible for them. The learning cycles of NGOs and housing units are in turn directed and supported by the municipal services, which in turn rely on learning taking place at the state level. At the same time, the learning taking place within a housing unit directs and supports learning in the neighborhood. Also the work within housing units constantly feeds developments and reorientations at the NGO, municipal and national levels. 
But what kind of learning takes place in each one of the cycles in Figure 1? Clarity on this is necessary if educational research is to contribute to processes such as the one on homelessness work in Finland. Once a homeless person becomes the resident of a supported housing unit, a long chain of work can start. This work is a learning journey toward the unknown. It is tailored work involving many parties and services, aimed at the functional independent living of the resident in his or her own home. This learning goes beyond the acquisition of well-established sets of knowledge and the participation in relatively stable practices. Each long-term homeless rescued from the street has a specific constellation of issues to address, requiring supportive interactions and tailored solutions co-designed with the client and changing as the client progresses or regresses. In activity theory, this learning is called expansive learning (Engeström, 1987/2015) entailing the stepwise process depicted in Figure 2.

\section{INSERT FIGURE 2 ABOUT HERE}

Figure 2. Steps in a cycle of expansive learning undertaken in a supported housing unit

The cycles in the unit of analysis may be seen as forming dense patterns with the grounding and resilience that can withstand setbacks. Turning to a useful metaphor, they can be conceived of as a thick rope pattern. This metaphor raises the question of what is the nature of the rope. The stronger the rope, the better expansive learning coalitions will face setbacks. Another question emerging from the metaphor of the rope is how one makes such strong ropes and such thick patterns out of them. Recent developments in activity theory point at a key conceptual resource for strong expansive learning patterns to come about: transformative agency by double stimulation (Sannino, 2015a and b; Sannino \& Laitinen, 2015; Sannino, 2016; Sannino, Engeström \& Lemos, 2016).

There is ample empirical evidence that expansive learning can lead to qualitative transformations both at the level of individual competences and knowhow and at the level of reorganization of collective activities and their broader contexts (Sannino, Daniels \& Gutièrrez, 2009; Sannino \& Ellis, 2013; Engeström, 2018). Learning by expanding, however, entails also the development of new visions and long-term engagement. That is why the recent literature points at transformative agency as a core process and outcome of expansive learning cycles.

Originally described by Vygotsky (1997/1931), transformative agency by double stimulation is a process by which human beings can intentionally break out of conflicting motives and change their circumstances. The process is depicted in Figure 3.

\section{INSERT FIGURE 3 ABOUT HERE}

Figure 3. The process of emergence of transformative agency by double stimulation 
The starting point to understand this process is that demanding learning is never direct at the beginning; it is always mediated by concrete artifacts or linguistic tools that must be adopted and actively used by the learner (Vygotsky, 1981). This is the very nature of human learning: we need artifacts to develop and to transform the world around us in response to our needs. The learning of an individual or a collective who faces a demanding problem by taking up and using mediational means is at the same time a volitional action (Sannino, 2020; Tomaz et al, 2020). Within this perspective, the learning process in itself becomes radically agentive.

The volitional aspect of the process lies in particular in the confrontation with a problematic situation, which triggers a paralyzing conflict of motives (first stimulus). In trying to cope with the problem, learners turn to mediational means (second stimuli) and decide to rely on them when instances of the problematic situation reoccur (Sannino, 2020). Each new instance of the problematic situation is cognitively and emotionally critical in that it reactivates the conflicting motives. When learners actually put into use the second stimulus, this implementation helps them to gain control of and to transform the problematic situation into one that is more understandable and manageable. The repeated implementation of the second stimulus to deal with the problem or specific aspects of it strengthens the learners understanding of the problem and capacity to take further actions, which in turn strengthens the longitudinal "rope" of the expansive learning process. As a result both the problem situation and the learners are transformed.

In a housing unit with which the research team is collaborating, staff members who had worked for many years acting as a guards and controllers with the residents had a hard time to adjust to the FHF way of working. They were tangled up within an already consolidated mode of action which kept them locked up in an office space with a plexiglass window through which they could control those who entered or exited the unit. When a new unit manager was recruited and the NGO responsible for the unit gave the OK to eliminate this "wall" between the workers and the residents, a great turmoil started in the unit. Some of the workers were afraid of the residents and the idea of being in an open space with them without a protective wall in between was very difficult for them to accept. When the unit manager sat with them in the open space casually interacting with the residents or having oatmeal with them, a set of new mediating means (or second stimuli) became available to the workers.

A staff member in this unit might have been torn between the conflicting motive of sticking to the old guard-like way of approaching the residents and the new way of working (first stimulus). One day this staff member might have decided that next time he would meet this resident of whom he is so much afraid, he will ask him if he wants to have a cup of coffee (second stimulus) following the manager's example. When the staff member meets this resident the volitional action might be implemented or might not. If the volitional action is accomplished by implementing the second stimulus, the problem situation acquires a new meaning, becoming less paralyzing. Then by repeating over and again the process, transformative agency develops to the point that the staff member discovers new capabilities he had ignored before and qualities in the resident that he had equally ignored. Essentially this transformative agency process is a deliberately initiated conditioning process by an individual or a collective who deliberately resolves to learn a new way of working. This is crucially a self-designed and self-enforced conditioning (rather than a classic behaviouristic one) which builds up into novel modes of action and expansive learning.

On the basis of 25 years of activity-theoretical research using CL formative interventions (Sannino, Engeström \& Lemos, 2016; Sannino \& Engeström, 2017) in which double 
stimulation has been systematically implemented, we have strong empirical evidence to claim that the stepwise expansive learning cycle and the transformative agency process mutually induce one another. In other words, the process of transformative agency by double stimulation is instrumental for sustained expansive learning to occur. Steps in an expansive learning cycle are usually hard to undertake and can therefore be induced by double stimulation. In other words, double stimulation is likely to be mobilized throughout the expansive learning process as depicted in Figure 4.

\section{INSERT FIGURE 4 ABOUT HERE}

Figure 4. The stepwise expansive learning cycle and the transformative agency process mutually inducing one another

A main hypothesis the research agenda drafted here aims at testing is that expansive learning for enacted utopia can be sustained by mediation of a research team using theoretical and methodological resources from activity theory. In our current project, this means helping homelessness practitioners to identify the expansive learning cycles they are involved in and mobilizing targeted double stimulation to keep up the learning process also in difficult times.

\section{An example of a first implementation of the agenda}

Three CL interventions were conducted: one in a housing unit, one with city level actors and one with state level actors. The housing unit has been undertaking major steps to reorganize itself since March 2018. The unit offers supported housing for young residents. It has nearly 100 apartments for this clientele and staff is present 24/7. The unit is located in a well-off, politically conservative and centrally located neighbourhood and has received negative press frequently ever since its opening in 2012. In public debate, the residents are often considered as "addicts" who are deemed "everyone's least favourite neighbour."

To prepare the CL, two meetings took place in the unit with the managers of the NGO and of the unit and with the staff. Also 20 interviews were conducted and selected excerpts of those were used in the CL sessions as "mirror material" (or first stimuli). Six CL sessions were conducted in the housing unit over a period of four months. During the sessions managers of the NGO and of the unit, the staff of the unit (19 participants in total) and the research team jointly analyzed the change effort undertaken since March 2018. Figure 5 illustrates the outcome of this analysis.

\section{INSERT FIGURE 5 ABOUT HERE}

Figure 5. The triangular model of the activity system used as a second stimulus for the learning action of analysis with the housing unit practitioners

The empty triangular model ("mallit" in Finnish refers to models) was offered by the research team as a second stimulus in an attempt to trigger the learning action of analysis of the past 
activity ("ennen" in Finnish is past). During the CL the model was collectively filled. The participants named the subject of their past work activity "controller" ("valvoja" in Finnish) and the residents ("asukas"). In this sythem the workers used as their main tools the protected office ("info"), cameras ("kamerat"), entry bans ("portikielto"), and visiting bans ("vierailukielto"). The residents were identified as the object of activity, that is its leading motive and reason of existence. The activity was carried out with strict instructions and use of power ("tarkat ohieet, vallan käyttö"), a community of turfs, cliques and distant bosses ("reviit, kuppikunnat, esimiehet kaukana") and a strict division of labor between service counselors and housing counselors ("tiukka ero palvelu-ohjaaja, asumis-ohjaaja". The outcome of the relations and processes between the components of this activity system was that the residents were not well ("asukkaat eivät voineet hyvin").

The most acute pressures for change or contradictions (marked with lightning-shaped arrows) within the system were also jointly identified. The control tools they were using, the strict rules and division of labor were found to give rise to negative consequences for the wellbeing of the residents. Also the nationwide quality recommendations of FHF were in place in the unit in such a way that they collided with a view of autonomy that would support the residents rather than "living them alone," to paraphrase the words of the NGO's service director responsible for the unit. The autonomy of each resident was so extensively respected that "for instance, if a resident said, 'I do not want to talk to you anymore', he or she has been left alone. ... A different kind of interpretation of the residents' autonomy requires, however, taking a lengthy effort."

The adoption of the activity system model as a second stimulus made it possible for the practitioners to collectively grasp their experiences of conflicting motives in the unit and the systemic nature of the problem behind these experiences. This analysis of the past activity served as a starting point for the next step in the expansive learning process carried out in the housing unit, namely the modelling of the unit's new way of working, still using the triangular representation.

Another second stimulus was a four-field that charted the direction of change and an area of possibilities to design solutions to the problematic situation. This mapping of the unit's collective zone of proximal development is depicted in Figure 6.

\section{INSERT FIGURE 6 ABOUT HERE}

Figure 6. A four-field charting the area of possibilities for work development and design solutions

Two directions of development were identified with the practitioners: the horizontal one from "controller" ("valvoja" in Finnish) to "coach" and "fellow traveller" ("valmentaja" and "kanssakulkija" in Finnish). The vertical dimension extends from "closing up like a clam" to an unknown direction which was later defined as "open catalyst" ("avoin vaikuttaja" in Finnish). The expression "closing up like a clam" refers to the risk heavily experienced by the unit's personnel that because of the stigma of their clientele, they easily close up and 
become isolated within the unit. During the work on the four field, a staff member stated the following, making it explicit why the unit may tend to close up like a clam:

"The common view is that our residents have adopted their current state of being on their own will. They have themselves made the choice or they are just outcasts or evil for no reason. Many people think that this is just a useless job, they [the residents] do not deserve this."

The notion of 'open catalyst' indicates that the staff and the residents will take deliberate steps to open up and influence the society outside the unit against the stigma associated with the residents and the work in the unit. In the process of filling the four-field in the CL, the director of the NGO stated the following:

"When we organize open doors, people do not want to come to us, they do not want to see this. If they come, the unit is given some angry critique. Sometimes someone comes with a bunch of flowers, great job. Instead of us [staff] going into society and saying fine words, we would need an understanding that our clients can go to some fairs and present something. They are visible human beings as everyone else."

The participants identified the direction of development they were following - marked with the circle and the dotted arrow moving from left to right and slightly upward on Figure 6 . The participants then worked on identifying spearheads (marked with the arrows in the upper right area of the four-field) to make concrete steps toward the chosen direction. In other words, these spearheads illustrate the top projects that aim at adopting a consistent way of working as fellow travellers with the residents and opening up outwards to the society. 15 of such projects are now being designed with the commitment to be implemented by staff and residents. These spearhead projects include the creation of a football team with staff and resident players to compete with other teams in the area; putting together bands which will perform for gigs; developing services brought to the residents' homes in response to the reluctance of some health care professionals to enter the apartments (preferring instead to serve the clients in one of the common areas of the unit).

The next steps in the implementation of the research agenda involved additional partnerships and CLs at the city level (with one of the largest municipalities in Finland) and at the national level (with organizations and actors including the director of the national programme for the prevention of homelessness, four prominent NGOs, six cities, the nationwide network developers, and the largest non-profit provider of socially supported housing in the country). With these additional CLs the aim was to promote mutual learning across sectors, organizations and levels. After hearing about the intervention in the housing unit, actors at both levels were convinced that a CL process would be beneficial for learning and development of homelessness work also at their respective levels. The research-mediated collective design of new solutions within the unit therefore served as effective persuasive mediator with the city and the national level.

The hypothesis is that cross-fertilization among the levels may support learning to meet the newly emerging challenges, to maintain the FHF results obtained so far and to meaningfully expand on them. The results of the analyses and the new solutions stemming from them may serve as breeding ground and catalyst for reflection on and envisioning of new policy initiatives in dialogue with decision-makers. 
The city level CL was prepared with two meetings with the leading administrator responsible for the major transformations in the homelessness field in the city and 9 interviews with key actors representing the main sectors of homelessness work in the city. The CL was conducted in six sessions over a period of six months. The sessions were attended by 19 participants representing 11 organizations in the city and different levels of activity. This CL produced the participants' shared vision and a proposal for an action plan for the next phase of homelessness work in the city. The implementation and impact of these outcomes is currently being followed up.

The CL at the national level gathered 19 organizations and actors (23 participants in total) to define the new FHF 2.0 principle and the priorities for the next phase of homelessness work in the country. More specifically, the goals of the CL at the national level were (1) to discuss how the FHF principle is being implemented in the services for the homeless in Finland; (2) to lift up development needs of FHF and factors behind these needs; (3) to select central development needs of the FHF and to draft a tentative plan for further development of the FHF principle in the next four years.

Three meetings hosted by the director of the national FHF programme at the Ministry of Environment and the national Network Developers took place in preparation of the CL. Also 18 interviews with key actors of homelessness work were conducted, and selected excerpts of those were used in the CL sessions as "mirror material" (or first stimuli). The CL was conducted in six sessions over a period of six months in the premises of the largest non-profit provider of socially supported housing in the country. The Change Laboratory produced a proposal for continuation actions of homelessness work in Finland in the 2020s and defined a vision for a FHF 2.0 principle.

The CLs at the ground level of the housing unit and at the intermediate level of the city served as impulses for modelling solutions at the national level. Ground-level experiences and ideas articulated in the CLs in the unit and in the city fed the national level vision and action perspectives to be brought to the attention of political forces and decision-makers.

This cross-sectoral and cross-level context represent a new opportunity for expansive learning at work. Expansive learning in this context consists of joint reconceptualization efforts by a flexibly developing coalition of diverse actors pursuing one and the same societally contradictory objective: the functional independent living of the former homeless in a home of one's own. This is a highly tension-filled objective, due to the financial costs and extensive transformation it entails of mindsets, practices and material arrangements. Strong agentive actions of commitment (Sannino, 2008, 2010) and material implementation of commitments are needed to pursue such an objective. The concept of transformative agency (Sannino, 2015a) aptly captures these types of willful pursuits of enacting utopias for the common good.

The approach presented here is novel in that it consists of a research-based inquiry conducted in close collaboration with key operative stakeholders working on homelessness from the ground level of frontline work to the city level and to the state level. The role played by the research team conveys ways in which theoretical tools can contribute to bringing together multiple parties and serve as mediators for collaborative analyses to meet critical societal challenges. 


\section{Concluding remarks}

Poverty today includes increasing homelessness in wealthy societies, beside the developing countries. The growing numbers of homeless in affluent cities is particularly problematic because it can divert resources and focus from eradicating poverty in targeted areas in the Global South. The agenda presented here is an opening toward constructive interactions between the world of educational research and actors experiencing or responding to acute needs in our societies.

Recent analyses (e.g., Scott, 2015; Wooltorton et al, 2015) claim that research on learning should be more relevant and engaged in supporting struggles for fundamental human rights and the creation of equitable socio-economic conditions. A statement from the Abahlali movement of shack-dwellers in South Africa (2008) illustrates the divide between solutions offered to the neediest in the name of education as result of research in the field and concrete concerns of these communities:

"Always the solution is to 'educate the poor'. When we get cholera we must be educated about washing our hands when in fact we need clean water. When we get burnt we must be educated about fire when in fact we need electricity. This is just one way of blaming the poor for our suffering... We don't want to be educated to be good at surviving poverty on our own".

The idea of the agenda presented here is to engage research with the concrete work and concerted initiatives on enactment of utopias, to help counteracting in practice stabilized views of impossibility that feed stereotypes and prejudices, such as those contributing to the stigma of poverty and homelessness.

The FHF strategy and the way it is currently evolving are distinctively valuable examples of enacted utopias, conveying that eradicating homelessness is possible. Educational research on work and learning should increasingly aim at reflectively unpacking such processes of enacted utopias, in dialogue with practitioners and political actors. This is a largely unexplored area of inquiry and collaboration with the civil society that research in work and learning can fill. Documentation and analyses within this area should lead to supporting the renewal of expansive learning cycles, especially at their intersections between sectors and hierarchical levels.

\section{Acknowledgements}

A preliminary draft of the theoretical section of this article was presented in a keynote address I gave at the Researching Work and Learning Conference at Rhodes University in December 2017 in South Africa. In this context I received valuable feedback which helped the shaping of the agenda presented here. In particular I thank Professor Heila Lotz-Sisitka, Doctor Mutizwa Mukute and Doctor Charles Chikunda, and express all my gratitude to Doctor Victor Tichaona Pesanayi for the discussions we had during the conference.

The empirical example stems from a project on learning for the enacted utopia of eradicating homelessness that received no external funding. The project is funded with basic research resources from the Faculty of Education and Culture at Tampere University. For this, I wish to warmly thank former Dean Risto Honkonen and Dean Päivi Pahta for believing in this 
project. Members of the RESET research group Professor Emeritus Yrjö Engeström and Researcher, Docent Hannele Kerosuo are vital contributors to the project. Also, I am extremely grateful to the numerous experts and practitioners involved in the project for their trust and collaboration.

\section{References}

Abahlali baseMjondolo. (2008). Abahlali baseMjondolo statement on the xenophobic attacks in Johannesburg. Press statement, 21/5/2008.

Abbé Pierre Foundation \& FEANTSA (2018). Third overview of housing exclusion in Europe. Accessed 17 January 2020: https://www.feantsa.org/download/full-reporten1029873431323901915.pdf

ARA (2018). Homelessness in Finland 2018. Helsinki: ARA Housing Finance and Development Centre of Finland.

Bina, O., Inch, A., \& Pereira, L. (2020). Beyond techno-utopia and its discontents: On the role of utopianism and speculative fiction in shaping alternatives to the smart city imaginary. Futures, 115, 102475.

Barkin, J. S. (2020). Utopia and the Anthropocene. Global Environmental Politics, 20(1), 122-126.

Brandsen, T., Steen, T., \& Verschuere, B. (Eds.) (2018). Co-production and co-creation. Milton: Routledge.

Engeström, Y. (1987/2015). Learning by expanding: An activity-theoretical approach to developmental research (2nd ed.). Cambridge, UK: Cambridge University Press.

Engeström, Y. (2018). Expertise in transition: Expansive learning in medical work. Cambridge, UK: Cambridge University Press.

Engeström, Y., Rantavuori, J. \& Kerosuo, H. (2013). Expansive learning in a library: Actions, cycles and deviations from instruction intentions. Vocations and Learning, 6(1), 81-106.

Engeström, Y. \& Sannino, A. (2010). Studies of expansive learning: Foundations, findings and future challenges. Educational Research Review, 5, 1-24.

Engeström, Y. \& Sannino, A. (2011). Discursive manifestations of contradictions in organizational change efforts. Journal of Organizational Change Management, 24(3), 368387.

Eskelinen, T., Lakkala, K., Lohtaja, A. \& Moren, T. (2017). Puheenvuoro utopia on yhteiskunnallisten vaihtoehtojen etsimisen menetelmä. Futura, 1, 36-37.

Habermas, J. (2010). The concept of human dignity and the realistic utopia of human rights. Metaphilosophy, 41(4), 464-480. 
Helskyaho, R., Ohisalo, M. \& Turunen, S. (2018). Asunnottomat 2017. Helsinki: ARA.

Henley, J. (2019, June 3). 'It's a miracle': Helsinki's radical solution to homelessness. The Guardian. https://www.theguardian.com/cities/2019/jun/03/its-a-miracle-helsinkis-radicalsolution-to-homelessness

Karppinen, J. (2018). Varmista asuminen turva! AUNE väliraportti. Helsinki: Ministry of Environment.

Habermas, J. (2010). The concept of human dignity and the realistic utopia of human rights. Metaphilosophy, 41(4), 464-480.

Kerosuo, H. (2006). Boundaries in action: An activity-theoretical study of development, learning and change in health care for patients with multiple and chronic illnesses. Doctoral Dissertation. Helsinki: Unigrafia.

Kerosuo, H. (2017). Transformative agency and the development of knotworking in building design. In M. Goller \& S. Paloniemi (Eds.), Agency at work (pp. 331-350). Gewerbestrasse: Springer.

Kerosuo, H., \& Toiviainen, H. (2011). Expansive learning across workplace boundaries. International Journal of Educational Research, 50(1), 48-54.

Lakkala, K. \& Pyykkönen, M. (2018). Sosialismi ja utopia tänään: Vastausvuorossa Erik Olin Wright. Niin \& Näin, 1 .

Leont'ev, A. N. (1978). Activity, consciousness and personality. Englewood Cliffs, NJ: Prentice Hall.

Leont'ev, A. N. (1981). Problems of the development of the mind. Moscow: Progress.

Levitas, R. (2000). For utopia: The (limits of the) utopian function in late capitalist society. Critical Review of International Social and Political Philosophy, 3(2-3), 25-43.

Levitas, R. (2003). The elusive idea of utopia. History of the human sciences, 16(1), 1-10. Lotz-Sisitka, H. (2017). Education and the common good. In B. Jickling \& S. Sterling (Eds.), Post-sustainability and environmental education: Remaking education for the future (pp. 63-76). Cham, Switzerland: Springer.

Pleace, N., Knutagård, M., Granfelt, R. \& Culhane, D. (2016). The strategic response to homelessness in Finland. In N. Nichols \& C. Doberstein (Eds.), Exploring effective systems responses to homelessness (pp. 425-441). Toronto: The Homeless Hub Press.

Programme of Prime Minister Sanna Marin's Government (2019). Inclusive and competent Finland: A socially, economically and ecologically sustainable society. Accessed 17 January 2020:http://julkaisut.valtioneuvosto.fi/bitstream/handle/10024/161935/VN_2019_33.pdf?seq uence $=1 \&$ is Allowed $=y$

Sannino, A. (2008). From talk to action: Experiencing interlocution in developmental interventions. Mind, Culture, and Activity, 15(3), 234-257. 
Sannino, A. (Ed.) (2015a). The emergence of transformative agency and double stimulation. Special issue of Learning, Culture, and Social Interaction, 4.

Sannino, A. (2015b). The principle of double stimulation: A path to volitional action. Learning, Culture, and Social Interaction, 6, 1-15.

Sannino, A. (2016). Double stimulation in the waiting experiment with collectives. Integrative Psychological and Behavioral Science, 50(1), 142-173.

Sannino, A., Daniels, H. \& Gutierrez, K. (Eds.) (2009). Learning and expanding with activity theory. Cambridge: Cambridge University Press.

Sannino, A. \& Ellis, V. (Eds.) (2013). Learning and collective creativity. New York: Routledge.

Sannino, A., Engeström, Y., \& Lemos, M. (2016). Formative interventions for expansive learning and transformative agency. Journal of the Learning Sciences, 25(4), 599-633.

Sannino, A. \& Engeström, Y. (2017). Co-generation of societally impactful knowledge in Change Laboratories. Management Learning, 48(1), 80-96.

Sannino, A. \& Laitinen, A. (2015). Double stimulation in the waiting experiment: Testing a Vygotskian model of the emergence of volitional action. Learning, Culture, and Social Interaction, 4, 4-18.

Sannino, A. (2020). Transformative agency as warping: How collectives accomplish change amidst uncertainty. Pedagogy, Culture \& Society, in press.

Schunk, D. H. \& DiBenedetto, M. K. (2016). Self-efficacy theory in education. Handbook of motivation at school, 34-54.

Scott, W. (2015). Public understanding of sustainable development: Some implications for education. International Journal of Environmental \& Science Education, 10(2), 235-246.

Steen, T., Brandsen, T., \& Verschuere, B. (2018). The dark side of co-creation and coproduction: Seven Evils. In T. Brandsen, T. Steen, \& B. Verschuere (Eds.), Co-production and co-creation (pp. 284-293). Milton: Routledge.

Tomaz, V., Sannino, A., \& Engeström, Y. (2020). Mathematics and agency: Learning to manage money between indigenous and market-based logics of life. Cognition and Instruction, in press.

Virkkunen, J., \& Newnham, D. S. (2013). The Change Laboratory: A tool for collaborative development of work and education. Rotterdam, The Netherlands: Sense.

Vygotsky, L.S. (1981). The instrumental method in psychology. In J. V Wertsch (Ed.), The concept of activity in Soviet psychology (pp. 134-143). Armonk, NY: Sharpe. 
Vygotsky, L.S. (1997/1931). The history of development of higher mental functions, Chapter 12: Self-control. The collected works of L. S. Vygotsky. The history of the development of higher mental functions, Vol. 4. (pp. 207-219). New York: Plenum.

Wooltorton, S., Wilkinson, A., Horwitz, P., Bahn, S., Redmond, J., \& Dooley, J. (2015). Sustainability and action research in universities: Towards knowledge for organisational transformation. International Journal of Sustainability in Higher Education, 16(4), 424-439.

Wright, E. O. (2010). Envisioning real utopias. London: Verso.

Wright, E. O. (2016). Real utopias and the dilemmas of institutional transformation. Justice, Power \& Resistance 1(1): 33-52.

Y-Foundation (2017). A Home of Your Own: Housing First and Ending. Homelessness in Finland. Keuruu: Otava. Retrieved from: https://ysaatio.fi/assets/files/2018/01/A_Home_of_Your_Own_lowres_spreads.pdf 